\title{
Mathematical Modeling for Minimizing Costs in a Multilayer Multi- Product Reverse Supply Chain
}

\section{Hoda Mahmoudi ${ }^{1}$, Hamed Fazlollahtabar ${ }^{2,3 *}$ and Iraj Mahdavi ${ }^{1}$}

${ }^{1}$ Department of Industrial Engineering, Mazandaran University of Science and Technology, Babol, Iran

${ }^{2}$ Faculty of Industrial Engineering, Iran University of Science and Technology, Tehran, Iran

${ }^{3}$ Niroogostar Energy Optimization Research Group, Tehran, Iran

\begin{abstract}
There is a direct or forward currency of material or production in the commodity's traditional currency and industry managers emphasize on its control and management. This currency continues from suppliers to producers, distributors, retailers and ultimately consumers but in many industries there is another important currency in the supply chain that forms reversely and products will be returned from lower level of the supply chain to a higher level. Reverse logistic wants to manage and study reverse currencies or in other word backward currencies. In this research, we proposed mathematical modeling of reverse supply chain's costs. The presented model is an integer linear programming model for multi-layer, multi-product reverse supply chain that minimizes the products and parts transportation costs among centers and also sites launch, operation parts, maintenance and remanufacturing costs at the same time. We solve the proposed model using Lingo 9 software.
\end{abstract}

Keywords: Reverse supply chain; Mathematical modeling; Cost analysis

\section{Introduction}

With the increased environmental concerns and stringent environmental laws, reverse logistics have received growing attention throughout this decade. Reverse logistics can be defined as the logistics activities all the way from used products no longer required by the customer to products again usable in the market. The members of the European Union (EU), for instance, have committed themselves to develop, implement and enforce legislation that makes producers responsible for the collection, treatment, recycling and environmentally safe disposal of all electrical and electronic equipment [1]. Among those, a group of companies has gone further and achieved economic gains from the adoption of environment-friendly logistic networks. IBM, for instance, has profited from its programs to receive end-of-use products, promote second hand items internet auctions and dismantle equipment as a source of spare parts [2]. According to the findings of Rogers and Tibben-Lembke [3], the total logistics cost amounted to $\$ 862$ billion in 1997 and the total cost spent in reverse logistics is enormous that amounted to approximately $\$ 35$ billion which is around $4 \%$ of the total logistics cost in the same year. The concerns about energy saving, green legislation and the rise of electronic retaining are increasing.

Although most companies realize that the total processing cost of returned products is higher than the total manufacturing cost, it is found that strategic collections of returned products can lead to repetitive purchases and reduce the risk of fluctuating the material demand and cost. Implementation of reverse logistics especially in product returns would allow not only for savings in inventory carrying cost, transportation cost, and waste disposal cost due to returned products, but also for the improvement of customer loyalty and future sales. In a broader sense, reverse logistics refers to the distribution activities involved in product returns, source reduction, conservation, recycling, substitution, reuse, disposal, refurbishment, repair and remanufacturing [4].

Reverse logistics can be categorized various types according to the product recovery option. Thierry et al. [5], suggested various product recovery options as direct reuse, resale, repair, refurbishing, remanufacturing, cannibalization, and recycling. Also, these options are to be reclassified into three broad categories such as reuse, recycling, and remanufacturing. In reuse, the returned product can be used more than once in the same form after cleaning or reprocessing. On the other hand, recycling denotes material recovery without conserving any product structure. Finally, remanufacturing is an industrial process in which worn-out products are restored to like-new condition. Concerning reverse logistics, a lot of researches have been made on various fields and subjects such as reuse, recycling, remanufacturing logistics etc. In this paper, we propose a framework and a mathematical model for costs in a multilayer multi product in the reverse supply chain system.

This paper is organized as follows: In the next section, we introduce some key literatures relevant to this study. A general framework and problem definition for reverse supply chain, the mathematical model of the reverse supply chain and numerical experiments are presented in the following sections. Finally conclusions and further researches are addressed in the last section

\section{Related Literature}

For the last decade, increasing concerns over environmental degradation and increased opportunities for cost savings or revenues from returned products prompted some researchers to formulate more effective reverse logistics strategies. A good overview of quantitative models for recovery production planning and inventory control is given by Fleischmann et al. [6]. They survey the recently emerged field of reverse logistics and subdivide the field into three main areas, namely distribution planning, inventory control, and production planning.

${ }^{*}$ Corresponding author: Hamed Fazlollahtabar, Faculty of Industrial Engineering Iran University of Science and Technology, Tehran, Iran, E-mail: hfazl@iust.ac.ir

Received January 30, 2013; Accepted February 27, 2013; Published March 03 , 2013

Citation: Mahmoudi H, Fazlollahtabar H, Mahdavi I (2013) Mathematical Modeling for Minimizing Costs in a Multilayer Multi-Product Reverse Supply Chain. Ind Eng Manage 1: 105. doi:10.4172/2169-0316.1000105

Copyright: (c) 2013 Mahmoudi H, et al. This is an open-access article distributed under the terms of the Creative Commons Attribution License, which permits unrestricted use, distribution, and reproduction in any medium, provided the original author and source are credited. 
And they point out the lack of a general framework and mathematical model for the reverse logistics environment. Der Laan and Salomon [7] propose a hybrid manufacturing/remanufacturing system with stocking points for serviceable and remanufacture able products, which will be a part of our framework.

Jayaraman et al. [8] propose a general mixed-integer programming model and solution procedure for a reverse distribution problem focused on the strategic level. The model decides whether each remanufacturing facility is open considering the product return flow. In reuse logistics models, Kroon and Vrijens [9] reported a case study concerning the design of a logistics system for reusable transportation packages. The authors proposed a MIP (mixed integer programming), closely related to a classical un-capacitated warehouse location model. In recycling models, Barros et al. [10] proposed a mixed integer program model considered two-echelon location problems with capacity constraints based on a multi-level capacitated warehouse location problem. Pati et al. [11], they developed an approach based on a mixed integer goal programming model (MIGP) to solve the problem. The model studies the interrelationship between multiple objectives of a recycled paper distribution network. The objectives considered are reduction in reverse logistics cost.

In remanufacturing models, Kim et al. [12] discussed a notion of remanufacturing systems in the reverse logistics environment. They proposed a general framework in view of supply planning and developed a mathematical model to optimize the supply planning function. The model determines the quantity of products parts processed in the remanufacturing facilities subcontractors and the amount of parts purchased from the external suppliers while maximizing the total remanufacturing cost saving. Aras et al. [13] develop a non-linear model and tabu search solution approach for determining the locations of collection centers and the optimal purchase price of used products in simple profit maximizing reverse logistics network. Du and Evans [14] minimize tardiness and total costs for location and capacity decisions in closed-loop logistics network operated by third party logistics (3PL) providers. To solve the bi-objective MILP model, a hybrid scatter search method is developed. Also Ko and Evans [15] consider a network operated by a 3PL service provider and they present a MINLP model for the simultaneous design of the forward and return network. They develop a genetic algorithm-based heuristic to solve the complex Developed model.

Finally, Lee and Dong [16] develop an MILP model for integrated logistics network design for end-of-lease computer products. They consider a simple network with a single production center and a given number of hybrid distribution-collection facilities to be opened which they solve using tabu search. However, all of researches are found for some cost in reverse logistics. Our study focuses on a general framework and state total cost in reverse supply chain.

This paper proposes multi layers, multi products reverse supply chain problem which consists of; returning center, disassembly center, processing center, manufacturing center, recycling center, material center and distribution center which consider the minimizing of total costs in reverse supply chain for returned products.

\section{Problem Definition}

The reverse supply chain under study is multi-layer, multi-product. In the designed (planned) model, the returned products after collecting and inspecting divides into two groups of disassembling and not disassembling products. The products which can be taken parted to the parts will be sent to the disassembling centers and there, they will convert to the parts. There they divide into reusable and not reusable parts. The not reusable parts will rebut safely and the reusable parts will be sent to the processing center. In the remanufacturing process, according to the production center's demand, the parts which can be used again, after processing center will be sent to the remanufacturing center and after compounding with the other parts will be changed into new products and can return to the distribution chain. In the recycling process according to the recycling center's demand the disassembled parts (which can recover again) right after disassembling centers will be sent to the recycling centers for the purpose of producing the secondary materials. The configuration is shown in figure 1.

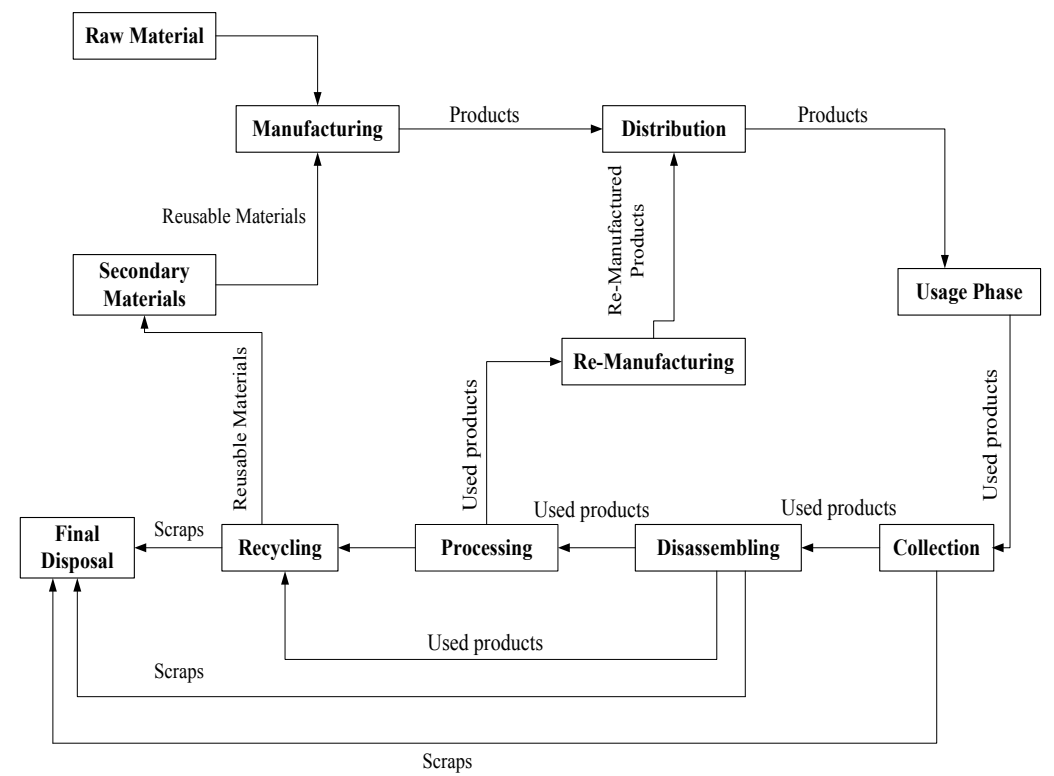

Figure 1: Framework for reverse supply chain 


\section{Purpose}

In this paper the reverse supply chain model has been considered for returned products with the purpose of minimizing the reverse supply chain costs.

- The quantity of return, disassembling, processing, manufacturing, recycling, material and distribution centers are determined.

- Some parts will be transported straightly from disassembling centers to the recycling centers.

\section{Indices, parameters and decision variables}

Indices:

i: index of returning centers

$\mathrm{j}$ : index of disassembly centers

$\mathrm{k}$ : index of processing center

$\mathrm{f}$ : index of manufacturing center

$r$ : index of recycling center

$\mathrm{w}:$ index of material

p: index of products

$\mathrm{m}$ : index of parts

l: index of distribution centers

c: index of distribution centers

\section{Parameters:}

$\mathrm{a}_{\mathrm{ip}}$ : the capacity of returning center i for product $\mathrm{p}$

$b_{j m}:$ the capacity of disassembly center $j$ for parts $m$

$\mathrm{u}_{\mathrm{km}}$ : the capacity of processing center $\mathrm{k}$ for part $\mathrm{m}$

Dream: the capacity of the recycling center is for part $\mathrm{m}$

$\mathrm{h}_{\mathrm{fm}}$ : the capacity of production center $\mathrm{f}$ for parts $\mathrm{m}$

$\mathrm{E}_{\mathrm{lm}}$ : the capacity of distribution center 1 for part $\mathrm{m}$

$\mathrm{DM}_{\mathrm{fm}}$ : the manufacturing center's demand $\mathrm{f}$ for part $\mathrm{m}$

$\mathrm{DRCM}_{\mathrm{rm}}$ : the recycling center's demand $\mathrm{r}$ for part $\mathrm{m}$

$\mathrm{DD}_{\mathrm{lm}}$ : the distribution center's demand 1 for part $\mathrm{m}$

$\mathrm{DC}_{\mathrm{cm}}$ : the client's demand $\mathrm{c}$ for part $\mathrm{m}$

$\mathrm{DMA}_{\mathrm{wm}}$ : the material center's demand $\mathrm{w}$ for part $\mathrm{m}$

$\mathrm{n}_{\mathrm{mp}}$ : the produced part's amount $\mathrm{m}$ from disassembling one product $\mathrm{p}$.

$\mathrm{CSRD}_{\mathrm{ijp}}$ : unit cost of transportation from returning center I to disassembly center $\mathrm{j}$ for product $\mathrm{p}$

$\operatorname{CSDP}_{\mathrm{jkm}}$ : unit cost of transportation from disassembly center $\mathrm{j}$ into processing center $\mathrm{k}$ for part $\mathrm{m}$

CSDRC $_{\text {irm }}$ : unit cost of transportation from disassembly center $j$ into the recycling center $\mathrm{r}$ for part $\mathrm{m}$

$\mathrm{CSPM}_{\mathrm{kfm}}$ : unit cost of transportation from processing center $\mathrm{k}$ into the manufacturing center $\mathrm{f}$ for part $\mathrm{m}$

$\mathrm{CSPRC}_{\mathrm{krm}}$ : unit cost of transportation from processing center into the recycling center $r$ for part $m$

$\mathrm{CSRCM}_{\mathrm{rwm}}$ : unit cost of transportation from recycling center are in the material center $\mathrm{w}$ for part $\mathrm{m}$

CSPDC $_{f m}$ : unit cost of transportation from manufacturing center $f$ into the distribution center $\mathrm{l}$ for part $\mathrm{m}$

$\mathrm{CSDC}_{\mathrm{lcm}}$ : unit cost of transportation from distribution center 1 into the clients $\mathrm{c}$ for part $\mathrm{m}$

FOCD $_{j m}$ : the fixed opening cost for disassembly center $\mathrm{j}$ for part $\mathrm{m}$ $\mathrm{FOCP}_{\mathrm{km}}$ : the fixed opening cost for processing center $\mathrm{k}$, for part $\mathrm{m}$ $\mathrm{FOCR}_{\mathrm{ip}}$ : the fixed opening cost for returning centers I for product $\mathrm{p}$ FOCRC $_{\mathrm{rm}}$ : the fixed opening cost for recycling centers $\mathrm{r}$ for part $\mathrm{m}$

$\mathrm{RMC}_{\mathrm{fm}}$ : unit cost of remanufacturing in manufacturing center $\mathrm{f}$ for part $m$

$\mathrm{IC}_{\mathrm{ip}}$ : unit cost of maintaining in returning center I for product $\mathrm{p}$

$\mathrm{OCD}_{\mathrm{jm}}$ : unit cost of operations in disassembly center $\mathrm{j}$ for part $\mathrm{m}$

$\mathrm{OCP}_{\mathrm{km}}$ : unit cost of operations in processing center $\mathrm{k}$ part $\mathrm{m}$

$\mathrm{OCRC}_{\mathrm{rm}}$ : unit cost of operations in recycling center $\mathrm{r}$ part $\mathrm{m}$

$\mathrm{NRS}_{\text {min }}$ : the minimum amount of returning center for opening and operations

NRS $_{\text {max }}$ the maximum amount of returning centers for operations and opening

$\mathrm{NDS}_{\min }$ : the minimum amount of disassembling centers for opening and operations

$\mathrm{NDS}_{\max }$ : the maximum quantity of disassembling centers for opening and operations

$\mathrm{NPS}_{\text {min }}$ : the minimum amount of processing centers for opening and operations

NPS $_{\max }$ : the maximum amount of processing centers for opening and operations

$\mathrm{NRCS}_{\text {min }}$ : the minimum amount of recycling centers for opening and operations

$\mathrm{NRCS}_{\text {max }}$ : the maximum amount of recycling centers for opening and operations

\section{Decision variables:}

$\phi_{\mathrm{ijp}}$ : amount shipped from returning center I to disassembling center $\mathrm{j}$ for product $\mathrm{p}$

$\mathrm{G}_{\mathrm{jkm}}$ : amount shipped from disassembly center $\mathrm{j}$ into the processing center $\mathrm{k}$ for part $\mathrm{m}$

$\mathrm{O}_{\mathrm{irm}}$ : amount shipped from disassembly center $\mathrm{j}$ into the recycling center $r$ for part $m$

$\mathrm{Q}_{\mathrm{kfm}}$ : amount shipped from the processing center into the manufacturing center $\mathrm{f}$ for part $\mathrm{m}$

$\mathrm{S}_{\mathrm{krm}}$ : amount shipped from processing center $\mathrm{k}$ into the recycling center $r$ for part $m$

$\rho_{\mathrm{rwm}}$ : amount shipped from recycling center $r$ into the material center $\mathrm{w}$ for part $\mathrm{m}$ 
$\mathrm{T}_{\mathrm{flm}}$ : amount shipped from manufacturing center $\mathrm{f}$ into the distribution center $\mathrm{l}$ for part $\mathrm{m}$

$\mathrm{V}_{\mathrm{lcm}}$ : amount shipped from distribution center 1 into the clients $\mathrm{c}$ for part $m$

$\alpha_{\mathrm{jm}}$ : if the disassembly center $\mathrm{j}$ is open for part $\mathrm{m}, 1$ or otherwise 0

$\beta_{\mathrm{km}}$ : if processing center $\mathrm{k}$ is open for part $\mathrm{m} 1$ or otherwise 0

$\gamma_{\mathrm{ip}}$ : if the collecting center $\mathrm{j}$ is open for product $\mathrm{p}, 1$ or otherwise 0

$\lambda_{\mathrm{rm}}:$ if recovery center $\mathrm{r}$ is open for part $\mathrm{m}, 1$ or otherwise 0

$\mu_{\mathrm{fm}}$ : the part's flow amount $\mathrm{m}$ in manufacturing center $\mathrm{f}$

$\mathrm{X}_{\mathrm{ip}}$ : the product's flow amount $\mathrm{p}$ in returning center $\mathrm{i}$

$\mathrm{Y}_{\mathrm{j} m}$ : the part's flow amount $\mathrm{m}$ in disassembly $\mathrm{j}$

$\theta_{\mathrm{km}}$ : the part's flow amount $\mathrm{m}$ in processing center $\mathrm{k}$

$\tau_{\mathrm{rm}}$ : the part's flow amount $\mathrm{m}$ in processing center $\mathrm{k}$

\section{Mathematical Formulation}

The formulation of the mathematical model is given below:

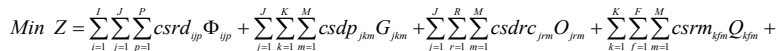

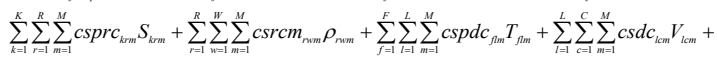

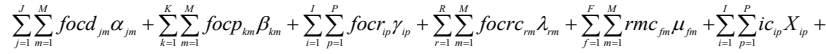

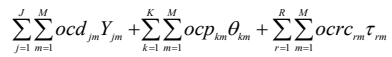

$$
\begin{aligned}
& \sum_{i=1}^{J} \Phi_{i j p} \leq a_{i p} \gamma_{p} \quad \forall i, p \\
& X_{\dot{p}} \leq a_{\dot{p}} \gamma_{\dot{p}} \quad \forall i, p \\
& \sum_{k=1}^{K} G_{j k m} \leq b_{j n} \alpha_{j m} \quad \forall j, m \\
& \sum_{r=1}^{R} O_{j r m} \leq b_{j n} \alpha_{j m} \quad \forall j, m \\
& Y_{j m} \leq b_{j n} \alpha_{j n} \quad \forall j, m \\
& \sum_{f=1}^{F} Q_{k f m} \leq u_{k m} \beta_{k m} \quad \forall k, m \\
& \sum_{r=1}^{R} S_{k r m} \leq u_{k m} \beta_{k m} \quad \forall k, m \\
& \theta_{k m} \leq u_{k m} \beta_{k m} \quad \forall k, m \\
& \sum^{W} \rho_{r w m} \leq d_{m} \lambda_{m} \quad \forall r, m \\
& \sum_{l=1}^{L} T_{f l m} \leq h_{f n} \quad \forall f, m \\
& \mu_{f n} \leq h_{f n} \quad \forall f, m \\
& \sum_{c=1}^{C} V_{l c m} \leq e_{m} \quad \forall l, m \\
& \sum_{k=1}^{K} Q_{k f m} \geq D M_{f m} \quad \forall f, m \\
& \mu_{f m} \geq D M_{f m} \quad \forall f, m \\
& \sum_{f=1}^{F} T_{f l m} \geq D D_{l m} \quad \forall l, m \\
& \sum_{l=1}^{L} V_{l c m} \geq D C_{c m} \quad \forall c, m
\end{aligned}
$$

$$
\begin{aligned}
& \sum_{r=1}^{R} \rho_{r w m} \geq D M A_{w m} \quad \forall w, m \\
& \sum_{j=1}^{J} O_{j r m}+\sum_{k=1}^{K} S_{k r m} \geq D R C M_{m} \quad \forall r, m \\
& \tau_{r m} \geq D R C M_{r m} \quad \forall r, m \\
& \sum_{j=1}^{J} \sum_{k=1}^{K} G_{j k m} \geq \sum_{f=1}^{F} D M_{f m} \quad \forall m \\
& \sum_{j=1}^{J} \sum_{k=1}^{K} G_{j k m} \leq n_{m p}\left(\sum_{i=1}^{I} \sum_{j=1}^{J} \Phi_{i j p}\right) \quad \forall m, p \\
& \sum_{j=1}^{J} \sum_{r=1}^{R} O_{j r m} \leq n_{m p}\left(\sum_{i=1}^{I} \sum_{j=1}^{J} \Phi_{i j p}\right) \quad \forall m, p \\
& N R S_{\min } \leq \sum_{i=1}^{I} \gamma_{\dot{p}} \leq N R S_{\max } \quad \forall p \\
& N D S_{\min } \leq \sum_{j=1}^{J} \alpha_{j n} \leq N D S_{\max } \quad \forall m \\
& N P S_{\min } \leq \sum_{k=1}^{K} \beta_{l o n} \leq N P S_{\max } \quad \forall m \\
& N R C S_{\text {min }} \leq \sum_{r=1}^{R} \lambda_{r m} \leq N R C S_{\text {max }} \quad \forall m \\
& \sum_{f=1}^{F} T_{f l m}=\sum_{c=1}^{C} V_{l c m} \quad \forall l, m \\
& \sum_{k=1}^{K} G_{j k m}+\sum_{r=1}^{R} O_{j r m} \leq Y_{j n} \quad \forall j, m \\
& \sum_{j=1}^{J} \Phi_{i j p} \leq X_{p} \quad \forall i, p \\
& \sum_{f=1}^{F} Q_{k f m}+\sum_{r=1}^{R} S_{k r m} \leq \theta_{k r} \quad \forall k, m \\
& \sum_{w=1}^{W} \rho_{r w m} \leq \tau_{m} \quad \forall r, m \\
& \sum_{l=1}^{L} T_{f l m} \leq \mu_{f n} \quad \forall f, m \\
& \Phi_{i j p}, G_{j k m}, O_{j r m}, Q_{k f m}, S_{k r m}, \rho_{r w m}, T_{f l m}, V_{l c m}, \mu_{f m}, X_{i p}, Y_{j m}, \theta_{k m}, \\
& \tau_{r m} \geq 0 \quad \forall i, j, k, f, r, w, p, m, l, c \\
& \alpha_{j m}, \beta_{k r}, \gamma_{\dot{p}}, \lambda_{m}=\{0,1\} \quad \forall i, j, k, p, m
\end{aligned}
$$

\section{Objective function:}

We want to demonstrate a model in reverse supply chain in a way to minimize the chain costs. We should introduce a model which minimizes the transportation cost of products and parts between centers and at the same time minimizes the fixed opening cost of sites and the operation's cost of parts and supply maintenance costs and remanufacturing costs. By attention to the definition of Indices, parameters and Decision variables; the objective function will be defined, which consists of : minimizing the costs of transportation of products and parts, the fixed opening cost of centers and operations costs on parts and the supply maintenance costs, remanufacturing costs in reverse supply chain (Equation 1).

\section{Constraints:}

(2) These constraints are decelerating that the amount of shipping 
products from any returning center (if it is open) into the disassembly center for each product should be equal or smaller than the capacity of that returning center.

(3) This constraint is stating that the amount of products which will be collected in the returning center should be equal or smaller than the capacity of that returning center.

(4) and (5) These constraints are stating that the amount of sent parts from any disassembly centers and recycling centers should be equal or smaller than the capacity of the same disassembly center for each part.

(6) This constraint is stating that the amount of a part which is in the disassembly center should be equal or smaller than the capacity of the same disassembly center.

(7) and (8) These constraints are stating that the amount of shipping parts from any processing centers (if it is opened) into the manufacturing centers and recycling centers should be equal or smaller than the capacity of the same processing centers for each part.

(9) This constraint is stating that the amount of a part which is in the processing center should be equal or smaller than the capacity of the same processing center.

(10) This constraint is stating that the amount of the parts which shipping from any recycling center (if it is open) into the material centers should be equal or smaller than the capacity of the same recycling for each part.

(11) This constraint states that the amount of sent parts from any manufacturing center into the distribution centers should be equal or smaller than the capacity of the same manufacturing center for each part.

(12) This constraint states that the amount of parts in each manufacturing center should be equal or smaller than the capacity of the same manufacturing center.

(13) This constraint states that the amount of sent parts from any distribution center to the client should be equal or smaller than the capacity of the same distribution center for clients.

(14) and (15) States the demand amount of the manufacturing center for pets

(16) States the part demand amount of distribution centers.

(17) Indicates the client's part demand amount.

(18) States the part demand amount of material center.

(19) and (20) States the part demand amount of recycling centers.

(21) States that the manufacturing center's demand is for parts which are transported from the disassembly center into the processing center

(22) and (23) these constraints are related to the balance of parts flow from the disassembly of products.

(24), (25), (26), (27) these constraints are stating that the min and max index amount of returning, disassembling, processing and recycling centers.

(28) This constraint states that the amount of sent parts from manufacturing centers in the distribution center is equal to the sent parts from distribution centers into the client.
(29) This constraint states that the amount of sent parts from each disassembly center into the processing and recycling centers should be equal or smaller than the parts amount in that disassembly center.

(30) These constraint states that the amount of sent products from each returning center into the disassembly, processing centers, should be equal or smaller than the product's amount in that returning center.

(31) These constraint states that the amount of sent parts from each of the processing centers into the manufacturing and recycling centers should be equal or smaller than the flow amount of parts in that processing center.

(32) This constraint states that the sent parts amount from any recycling center into the material centers should be equal or smaller than the parts amount in that recycling center.

(33) This constraint states that the sent parts amount from any manufacturing center into the distribution centers should be equal or smaller than the parts flow amount in that manufacturing center

(34) And (35) Enforce the binary and non- negativity restrictions on the corresponding decision variables.

\section{Numerical Experiment}

We solved the presented mathematic model by using Lingo 9 , which is an operation research software. In this multi layer and multi product model, we are attempting to minimize the costs of fixed opening facilities, transportation and shipping of products and parts between centers and also the operations, supply maintenance and remanufacturing costs, and also the product amount and sending parts into the centers and the amount of it would be calculated. To analyze the suggested model we create a numerical example in small size and then solves the created example by lingo software.

In small size we consider the index quantities as variables between 3 to5 to solve the problem, so we replace the inputs of problem in the model and by using the lingo we will solve the problem and finally; the model solving outputs and the objective function amount and the implementation time of it would be demonstrated.

By attention to the inputs of the model and solving it, the outputs of the model and objective function amount and the implementation time has been obtained which are as follows:

The obtained objective function is 29653.20 which obtained in zero time. All the variables which were not zero 0 quantities are shown in table 1.

After solving the model we will find out that the decision variable $a(1,2)$ gained 1quantity. This means that the disassembly center 1 should be opened for part 2 . The decision variable $\lambda(3,2)$ obtained 1 , means that the recycling center 3 would be opened for part 2 . Generally when the decision variables $\alpha_{\mathrm{im}}, \beta_{\mathrm{km}}, \gamma_{\mathrm{ip}}, \lambda_{\mathrm{rm}}$ gained 1, it indicates that the considered center to that decision variable will be opened for that part or product.

The decision variable $\mathrm{Q}(1,4,2)$ is considered 5 . This means that the amount of part 2 from processing center 1 into the manufacturing center 4 is 5 . The decision variable $\tau(2,3)$ got 15 , it means that the amount of part 3 in recycling center 2 is $15 . \rho(3,2,2) 8=$ means that the amount of part 2 from recycling center 3 into the material center 2 is 8 . 
Citation: Mahmoudi H, Fazlollahtabar H, Mahdavi I (2013) Mathematical Modeling for Minimizing Costs in a Multilayer Multi-Product Reverse Supply Chain. Ind Eng Manage 1: 105. doi:10.4172/2169-0316.1000105

Page 6 of 6

\begin{tabular}{|c|c|c|c|c|c|}
\hline$\varphi(2,1,4)$ & 1.2 & $\rho(3,3,2)$ & 14 & $\theta(1,2)$ & 57 \\
\hline$\varphi(2,3,2)$ & 0.9 & $\mathrm{~T}(1,1,3)$ & 6 & $\theta(2,2)$ & 16 \\
\hline$\varphi(3,3,1)$ & 0.9 & $\mathrm{~T}(1,2,1)$ & 8 & $\theta(2,3)$ & 63 \\
\hline$\varphi(3,3,3)$ & 1.1 & $\mathrm{~T}(1,2,3)$ & 13 & $\theta(3,1)$ & 8 \\
\hline $\mathrm{G}(1,3,2)$ & 62 & $\mathrm{~T}(1,3,2)$ & 3 & $\theta(4,2)$ & 20 \\
\hline $\mathrm{G}(1,4,3)$ & 50 & $\mathrm{~T}(2,1,2)$ & 7 & $\theta(4,3)$ & 7 \\
\hline $\mathrm{G}(2,1,3)$ & 16 & $\mathrm{~T}(2,2,3)$ & 17 & $\gamma(2,1)$ & 1 \\
\hline $\mathrm{G}(3,2,1)$ & 59 & $\mathrm{~T}(2,3,1)$ & 24 & $\gamma(2,2)$ & 1 \\
\hline $\mathrm{O}(1,1,3)$ & 8 & $\mathrm{~T}(2,3,3)$ & 16 & $\gamma(2,3)$ & 1 \\
\hline $\mathrm{O}(1,3,2)$ & 18 & $\mathrm{~T}(3,2,1)$ & 8 & $\gamma(2,4)$ & 1 \\
\hline $\mathrm{O}(1,3,3)$ & 4 & $\mathrm{~T}(3,2,2)$ & 8 & $\gamma(3,1)$ & 1 \\
\hline $\mathrm{O}(2,2,3)$ & 4 & $\mathrm{~T}(4,1,1)$ & 13 & $(3,2)$ & 1 \\
\hline $\mathrm{O}(2,3,1)$ & 18 & $\mathrm{~T}(4,2,1)$ & 3 & $\gamma(3,3)$ & 1 \\
\hline$Q(1,1,1)$ & 9 & $\mathrm{~T}(4,2,2)$ & 5 & $\gamma(3,4)$ & 1 \\
\hline$Q(1,1,2)$ & 17 & $\mathrm{~T}(5,1,1)$ & 8 & $X(2,2)$ & 0.87 \\
\hline $\mathrm{Q}(1,2,1)$ & 18 & $\mathrm{~T}(5,1,2)$ & 16 & $X(2,4)$ & 1.19 \\
\hline $\mathrm{Q}(1,2,2)$ & 16 & $\mathrm{~T}(5,3,3)$ & 17 & $X(3,1)$ & 0.94 \\
\hline $\mathrm{Q}(1,3,2)$ & 8 & $\mathrm{~V}(1,1,2)$ & 6 & $X(3,3)$ & 1.09 \\
\hline $\mathrm{Q}(1,4,1)$ & 16 & $V(1,1,3)$ & 6 & $\lambda(1,1)$ & 1 \\
\hline $\mathrm{Q}(1,4,2)$ & 5 & $V(1,2,2)$ & 17 & $\lambda(1,2)$ & 1 \\
\hline $\mathrm{Q}(1,5,1)$ & 8 & $V(1,3,1)$ & 1 & $\lambda(1,3)$ & 1 \\
\hline $\mathrm{Q}(2,1,3)$ & 19 & $\mathrm{~V}(1,4,1)$ & 20 & $\lambda(2,1)$ & 1 \\
\hline $\mathrm{Q}(2,3,3)$ & 14 & $V(2,1,2)$ & 4 & $\lambda(2,2)$ & 1 \\
\hline $\mathrm{Q}(2,4,3)$ & 9 & $\mathrm{~V}(2,2,3)$ & 16 & $\lambda(2,3)$ & 1 \\
\hline$Q(2,5,2)$ & 16 & $\mathrm{~V}(2,3,1)$ & 19 & $\lambda(3,1)$ & 1 \\
\hline$Q(2,5,3)$ & 17 & $V(2,4,2)$ & 9 & $\lambda(3,2)$ & 1 \\
\hline $\mathrm{Q}(3,3,1)$ & 8 & $V(2,4,3)$ & 14 & $\tau(1,1)$ & 32 \\
\hline $\mathrm{Q}(4,2,3)$ & 7 & $\mathrm{~V}(3,1,1)$ & 20 & $\tau(1,2)$ & 20 \\
\hline$S(1,1,1)$ & 16 & $\mathrm{~V}(3,1,3)$ & 13 & $\tau(1,3)$ & 12 \\
\hline $\mathrm{S}(1,2,1)$ & 4 & $\mathrm{~V}(3,2,1)$ & 4 & $\tau(2,1)$ & 17 \\
\hline$S(1,2,2)$ & 11 & $V(3,3,2)$ & 3 & $\tau(2,2)$ & 11 \\
\hline$S(2,1,3)$ & 4 & $V(3,3,3)$ & 20 & $\tau(2,3)$ & 15 \\
\hline$S(4,1,2)$ & 20 & $\alpha(1,2)$ & 1 & $\tau(3,1)$ & 18 \\
\hline$\rho(1,1,1)$ & 1 & $\alpha(1,3)$ & 1 & $\tau(3,2)$ & 25 \\
\hline$\rho(1,1,2)$ & 12 & $\alpha(2,1)$ & 1 & $\tau(3,3)$ & 4 \\
\hline$\rho(1,2,1)$ & 17 & $\alpha(2,2)$ & 1 & $\mu(1,1)$ & 9 \\
\hline$\rho(1,2,3)$ & 6 & $\alpha(2,3)$ & 1 & $\mu(1,2)$ & 17 \\
\hline$\rho(1,4,1)$ & 14 & $\alpha(3,1)$ & 1 & $\mu(1,3)$ & 19 \\
\hline$\rho(1,4,3)$ & 2 & $Y(1,2)$ & 80 & $\mu(2,1)$ & 24 \\
\hline$\rho(1,5,2)$ & 8 & $Y(1,3)$ & 62 & $\mu(2,2)$ & 16 \\
\hline$\rho(1,5,3)$ & 4 & $Y(2,1)$ & 18 & $\mu(2,3)$ & 33 \\
\hline$\rho(2,1,3)$ & 1 & $Y(2,3)$ & 20 & $\mu(3,1)$ & 8 \\
\hline$\rho(2,3,1)$ & 1 & $Y(3,1)$ & 59 & $\mu(3,2)$ & 8 \\
\hline$\rho(2,3,3)$ & 1 & $\beta(1,1)$ & 1 & $\mu(3,3)$ & 14 \\
\hline$\rho(2,4,2)$ & 4 & $\beta(1,2)$ & 1 & $\mu(4,1)$ & 16 \\
\hline$\rho(2,5,1)$ & 16 & $\beta(2,2)$ & 1 & $\mu(4,2)$ & 5 \\
\hline$\rho(2,5,2)$ & 7 & $\beta(2,3)$ & 1 & $\mu(4,3)$ & 9 \\
\hline$\rho(2,5,3)$ & 13 & $\beta(3,1)$ & 1 & $\mu(5,1)$ & 8 \\
\hline$\rho(3,1,2)$ & 3 & $\beta(4,2)$ & 1 & $\mu(5,2)$ & 16 \\
\hline$\rho(3,2,2)$ & 8 & $\beta(4,3)$ & 1 & $\mu(5,3)$ & 17 \\
\hline$\rho(3,3,1)$ & 18 & $\theta(1,1)$ & 71 & & \\
\hline
\end{tabular}

\section{Conclusion}

In this paper, a reverse supply chain was considered is minimizing the total cost of transport, inspection, remanufacture and maintenance. The presented model was an integer linear programming model for multi-layer, multi-product reverse supply chain that minimizes the products and parts transportation costs among centers and also sites launch, operation parts, maintenance and remanufacturing costs at the same time. We solved the proposed model using Lingo 9 software.

\section{References}

1. http://eur-lex.europa.eu/LexUriServ/LexUriServ.do?uri=OJ:L:2003:037:0024:0 038:en:PDF.

2. Fleischmann M, Van Nunen JAEE, Grave B (2003) Integrating closed-loop supply chains and spare-parts management at IBM. Interfaces 33: 44-56.

3. Rogers DS, Tibben-Lembke RS (1999) Going backward: reverse logistics trends and practices. Nevada, Reno: Reverse Logistics Executive Council.

4. Stock JK (1992) Reverse logistics, white paper, council of logistics management IL: Oak Brook.

5. Thierry M, Salomon M, Nunen JV, Wassenhove LV (1995) Strategic issues in product recovery management. Calif Manage Rev 37: 114-135.

6. Fleischmann M, Bloemhof-Ruwarrd JM, Dekker R, Der Lann E, Nunen JAEE, Wassenhove LN (1997) Quantitative models for reverse logistics: a review. Eu J Oper Res 103: 1-17.

7. Der Laan E, Salomon M (1997) Production planning and inventory control with remanufacturing and disposal. Eur J Oper Res 102: 264-278.

8. Jayaraman V, Patterson RA, Rolland E (2003) The design of reverse distribution networks: models and solution procedures. Eur J Oper Res 150: 128-149.

9. Kroon L, Vrijens G (1995) Returnable containers: An example of reverse logistics. International Journal of Physical Distribution \& Logistics Management 25: 56-68.

10. Barros AI, Dekker R, Scholten VA (1998) A two-level network for recycling sand A case study. Eur J Oper Res 110: 199-214.

11. Pati RK, Vrat $P$, Kumar $P$ (2008) A goal programming model for paper recycling system. The International Journal of Management Science, Omega 36: 405-417.

12. Kim K, Song I, Kim J, Jeong B (2006) Supply planning model for remanufacturing system in reverse logistics environment. Comput Ind Eng 51: 279-287.

13. Aras N, Aksen D, Tanugur AG (2008) Locating collection centers for incentivedependent returns under a pick-up policy with capacitated vehicles. Eur J Ope Res 191: 1223-1240.

14. Du F, Evans GW (2008) A bi-objective reverse logistics network analysis fo post-sale service. Comput Oper Res 35: 2617-2634.

15. Ko HJ, Evans GW (2007) A genetic algorithm-based heuristic for the dynamic integrated forward/reverse logistics network for 3PLs. Comput Oper Res 34 346-366

16. Lee DH, Dong M (2008) A heuristic approach to logistics network design fo end-of-lease computer products recovery. Transport Res E-Log 44: 455-474.

Table 1: Numerical results using LINGO 9 Software. 